Erik Zeltner*

DOI: $10.18290 /$ pepsi-2019-0010

\title{
Career Transition of Non-European Graduates from European Higher Education Institutions: Implications for Career Practice
}

\section{ABSTRACT}

Based on several case studies of career services for international students and the transitional experience of non-European graduates from study to work, I provide an integrated analysis of transcripts of semi-structured interviews conducted with career representatives and non-European graduates from German, UK and Dutch universities. I discuss the implications for career practice in light of individual perspectives of non-European graduates, higher education career services and other related institutions. The article reveals factors for career planning and development considering cultural gaps ranging from language issues to differences in the higher education system or recruitment procedures as well as a lack of career provision for international students. It illustrates how career services have reacted to these issues by creating new strategies, including the job role of a career specialist for international students, and suggests new directions for further research and the career development of non-European graduates with regard to participating universities and from a broader institutional perspective.

KEYWORDS: career service, international student mobility, study to work, acculturation.

* Correspondence regarding the paper should be sent to: Erik Zeltner, www. entre2c.eu (Austria), e-mail: e.zeltner@warwickgrad.net 
For international graduates from European higher education institutions (HEIs), their rising numbers and the attempts to utilize their international experience in a globalized labor market result in an increasingly challenging transition period. This development is accompanied by the students' intention to stay in the respective host country after graduation, which is consistently above $60 \%$ in several European countries (Sykes \& Chaoimh, 2012); also, there is a discrepancy between this intention to stay and the actual stay rates of European host countries (Hanganu, 2015; Home Office, 2018). Moreover, data suggest that recent nonEuropean graduates are more likely to be unemployed than their European colleagues or must contend with longer periods of unemployment (Hanganu \& Heß, 2014; Higher Education Statistics Agency [HESA], 2016). Furthermore, international experience is not necessarily a key factor in recruitment (Van Mol, 2016) and recruiters are often unable to appreciate the competencies gained through international experience, or else graduates are unable to promote their skills effectively to employers (Leppanen, Saarinen, Nupponen, \& Airas, 2014). Regardless of whether graduates can stay, return home or establish a career elsewhere, the transition process is often accompanied by the challenges of (re)entry and (re)acculturation (Zhou, Jindal-Snape, Topping, \& Todman, 2008).

Host countries benefit financially from non-European students, and the introduction of tuition fees in the UK caused a significant change in the strategy of most HEIs. Besides the focus on research, graduate employability became top of the agenda. This also affected career centers in higher education (HE) and caused a significant rise in staff numbers and these employees became influential within HEIs and in the HE sector. In continental European countries, the institutional establishment of career centers is still lagging with the foundation of the majority of smaller centers a decade ago. Despite this development, there is still a lack of HE career provision for international students in the UK and 
Germany (Equality Challenge Unit [ECU], 2012; Ripmeester \& Pollock, 2013).

For these reasons, I tried to gain an overview and more indepth knowledge regarding career provision for international students and the transition of non-European master's graduates from study to work (Zeltner, 2018a, 2018b). In light of these findings, I discuss the implications for career practice at different levels, such as the individual perspective of non-European graduates, the career service management and other institutions related to policy making and social systems interventions with regard to the tasks in career guidance and counseling, as defined by Network for Innovation in Career Guidance and Counselling in Europe [NICE] (2016).

\section{CAREER PROVISION AND TRANSITION: EMPIRICAL BACKGROUND}

The existing research focuses mainly on the national situation of HE career services (Brandl, 2015) and seldom includes the needs of services for international students, or they concentrate on one country or HEI (Coombes, 2014). Partly, the International Student Barometer focuses on career issues from an international perspective and it has revealed a lack of career provision in Germany. The results show that students are often unaware of the services offered or hesitate to make use of them (Ripmeester $\&$ Pollock, 2013). A lack in career provision is also visible in the UK, where the satisfaction of international students with services of one-to-one support and workshops is high. However, 58\% of those students who indicated dissatisfaction with career services were international students (ECU, 2012). One of the reasons for dissatisfaction was the view that services are not sufficiently internationally focused, especially for non-European students. 
Quantitative research on issues of employability and the competencies gained through degree mobility ${ }^{1}$ is often fragmentary and hardly comparable, or representative data are not in place yet (Mühleck, 2015). Moreover, the aspects of non-European graduates are not considered. Besides prolonged periods of unemployment among non-European graduates, degree-mobile students are often confronted with a lack of professional networks in the host or their home countries or with limited familiarity of students and employers in the domestic and foreign labor markets (Wiers-Jenssen, 2011).

Qualitative research and case studies of transition of nonEuropean graduates in light of their career development and implications for career practice are hardly available or have not been published. Some studies focus on intra-European mobility (Tzanakou \& Behle, 2017). However, they do not take cross-cultural aspects of transition into account nor do they try to make links to career services. Given the fact that non-European students can be considered as strategic success factors in financial terms or in terms of valuable human capital for host countries, it is surprising that this field is under-researched so far. This paper contributes toward this area of research.

\section{RESEARCH METHODS}

For the two research projects which I have carried out, I chose the research strategy of multiple case studies (Yin, 2009). The first one comprises a contrasting analysis of seven European HEIs and their career provision for international students, including services, strategy and marketing (Zeltner, 2018a). During the second project, I analyzed relevant individual and societal

${ }^{1}$ Degree mobility is a type of student mobility involving students who are enrolled to complete a full degree in a university outside of their country. 
factors for non-European graduates from German and British HEIs regarding their cross-cultural and professional transition from study to work (Zeltner, 2018b). The findings included the identification of cross-cultural gaps, cultural preparedness and acculturation strategies of these graduates as well as their career progression and management, with a focus on stages, processes and patterns of change. For the analysis, I made use of theoretical concepts derived from the acculturation process model of Zhou et al. (2008) and from career development, such as the theories of social learning (Mitchell \& Krumboltz, 1996) or the change model of Prochaska, DiClemente, and Norcross (1992).

Because of the explorative character of both studies, I focused on qualitative research methods. In terms of data collection methods, I chose three different sources of evidence. I used the results of quantitative studies from the initial literature review and further reviews based on the analysis of the interview transcripts. The second source was the transcripts of 12 semi-structured, audio-recorded Skype interviews that I conducted with six graduates from a German and another six from a British HEI. Third, I obtained some information from German, British and Dutch HEIs, and included the transcripts of semi-structured, audiorecorded, face-to-face interviews with a career representative of each HEI. This also included written sources, such as workshop offers or training handbooks.

I employed a convenience sampling procedure, so I dealt with HEI career services using a high number of international students. At two HEIs, the career representatives acted on my behalf and targeted some of their recent graduates and invited them to participate in my research. All interviewees signed a consent form, including anonymity and confidentiality of participants and HEIs. ${ }^{2}$

2 This article is aimed at career practitioners. Further information about research methods can be obtained by request. 


\section{INDIVIDUAL PERSPECTIVES}

All interviewees undertook extensive planning periods before studying abroad. However, in some cases there appeared to be a discrepancy in their career planning. This contradiction arose from the strict visa legislation for non-European graduates, who usually have to leave the UK after graduation but this country is their preferred destination after studies. Two graduates from the British sample expressed deep regrets about their choice and their unsuccessful attempts to enter the British labor market. Both of them were highly satisfied with their courses. However, they also stated that they should have chosen a different country in terms of visa legislation with better prospects for entering the host labor market.

Another factor to be considered is the benefits of internships for professional and cross-cultural transition - six out of seven interviewees became employed through an internship provider directly after graduation - which turned out to be a key success factor regarding the labor market entrance of the host country. For the graduates from the German HEI, the internship gave them the chance to obtain their employers' confidence. This turned out to be a distinctive advantage in the recruitment process thereafter. The graduates of the British HEI faced more difficulties in getting a placement. One reason had to do with the strict rules for working on a tier 4 student visa, which involves disadvantages for non-European full-time master's students. This is because only a small number of master's programs include the option of a short term internship where students are eligible to work more than 20 hours per week. An Indian graduate expressed deep regrets when he realized this.

I just wished I did my bachelor's there, because bachelor's international students get better placements than international master's 
students. So I really wished I did my bachelor's there and I would have gotten my placement and things would have been as I hoped.

A third factor is language proficiency in the host country and its consequences. While in the UK language courses are congruent with the country's language, this is different in Germany and all graduates of my sample underestimated the relevance of German for labor-market entry and everyday life. Consequently, none of the interviewees were prepared, and their arrival at the German HEI and the first period of integration were associated with such key words as 'roller coaster' and 'nightmare' or feelings of loneliness. Besides the effects on well-being, poor command of the language had a negative impact on the duration of study, and the graduates from the German sample needed four years on average to finish their two-year master's degrees. Surprisingly, nobody undertook a longer pre-sessional course in German in combination with a strong integration into German society prior to the studies. This could have had positive effects on cultural preparedness, duration of the study and its management, allowing students to enter the German labor market more effectively. The case of an Iraqi from the British sample illustrates the benefits of such kind of courses.

At the first two months it was quite difficult and I felt, I am depressed and from the early beginning on I got what they call a culture shock, because I am not adapted to the styles of banking, shopping, the new culture. I faced difficulties with the language, but at least I started the progression in my English course. I settled there and I built a new relationship with some international students and with some tutors who were really helpful and friendly. After six months it felt like my second home city and I thought about to settle forever there. 
Two other factors could be identified that result from cultural and institutional characteristics and could be considered as success factors for transition. For the British graduates, it was time management, particularly when dealing with the challenges of studying while job searching in parallel in a short period of one year. An Indian graduate from the British HEI put it in a nutshell like this:

I learnt a lot about how to manage my time because in the UK time is everything. All of my professors stressed time and made me more functional and that helped me gain a lot of respect with my colleagues here in the UAE.

As for the German sample, it was concerned with the quality of being proactive, especially when identifying, organizing and making use of support structures as well as acquiring internships or graduate jobs on one's own initiative. The head of the career services described this cultural approach like this: 'higher education (in Germany) is not there to be nice, and it doesn't mean that I (the student) get pampered'. A Nepalese graduate from Germany, who was the only one who had already completed his bachelor's degree abroad at a German university, an Anglophone HEI with a typical Anglo-American culture, outlined the differences of both systems.

While I was in [1st HEI], I was living in a bubble because it was a kind of a campus culture. So, you spent almost all your time within the university compound. I guess when I came to [2nd HEI], I had the experience that most of the foreign students have, when they come to Germany, because going to [1st HEI] was different. University took care of most of the things. You lived within the university housing and you didn't have to look for housing and you eat at the cafeteria in the university, and for your parttime jobs you can look outside the university as well, but there 
were many options within the university. It was as if you were sought-after, kind of a bit, and it was not like that in [2nd HEI]. I had to take care of everything and you had to start from scratch.

In terms of the transition from study to work, the cases of the non-European graduates from Germany portray a broad variety of acculturation strategies starting off from a high level of cultural distance and ending up in the German or other international labor markets. The complexity of this cultural transition and its acculturation cannot only be seen as a transition from one cultural system to another but needs to take the multilayered combinations of mono-, bi- and multicultural social environments into account, where non-European students and graduates reside or pass through. Bringing career management, goals and destinations into accordance with the students' or graduates' preferred social and cultural environment is the main challenge of transition in terms of professional success and personal well-being. In some cases of this research, graduates have reached a high level of congruency but in others they are still in an incongruent state regarding their transition. An Indian graduate, who had to change his preferred industry, provides an illustrative example. He became hired by a midsized company in a rural region in Germany, where he was the first engineer holding a tertiary degree.

Meanwhile, I have friendships with few of my colleagues over here. I have a really very good community in Germany, but they are far off. If I move to a bigger city in Germany, it really gets much, much easier. But I will stay here at least over three to four years. I am thinking of getting a residency over here, permanent residency. Once I get that, it will be easier for me to move around.

Consequently, for some of them, the professional transition, and for most of them, the cross-cultural transition, was considered an ongoing process. 


\section{IMPLICATIONS FOR CAREER SERVICES}

Firstly, the graduates from the German HEI were highly satisfied with the one-to-one sessions and workshops provided by the career center. However, they also demanded more workshops, addressed particularly to international students. Secondly, and this goes along with findings from the study by Ripmeester and Pollock (2013), there is a perceived lack of information about opportunities and making use of the benefits of career services. Furthermore, the narratives show that there is a need to address cross-cultural and professional issues more effectively and for tailored marketing of services for international students. Finally, as a result of the first two points, the strategy adopted for the target group of international students would need to be defined and implemented. Both the graduates and the head of careers stated that they would welcome a career specialist providing more targeted services.

In the UK, the role of a career specialist was introduced only a few years ago at some HEIs and is adjusted to the strategy of the career service. It involves a specialist and an international PhD student ambassador team. Together they provide workshops for international students, addressing career and cross-cultural issues. They provide information about the services; and organize further activities and events, such as a monthly career club, where ambassadors and international students get together and share experiences in an informal setting (Zeltner, 2018a). A similar structure would also be feasible for the German HEI. Because German PhD candidates are usually employed by HEIs with higher salaries than their UK counterparts, the ambassador team could alternatively be formed from international master's students because of their long duration of study. Official figures of the HEI from 2017 reveal that the average of the actual duration of studies for master's students in most subjects that are popular among international students is close to three years. 
The strategy could also involve workshops related to crosscultural and career-related learning and be tailored around cross-cultural transition and designed considering identified cultural gaps, preparedness and acculturation strategies as well as societal and institutional differences of the students' home and host countries. In addition, stories of former students could be presented, analyzed and discussed, with the aim to improve the understanding of career transition and its challenges and success factors, as well as its typically underlying processes and patterns of career change. A curricular integration of such kinds of workshops would be most effective for those faculties with courses offered in English with a high number of international students, and mandatory internships as part of the program, with the aim of meeting corporate demand and skills shortage in certain industries. Furthermore, they could inform and motivate students to make use of extracurricular workshops and one-to-one sessions offered by career services, which are more focused on the provision of traditional career topics of implementation, such as writing applications or training with mock interviews and assessment centers.

The German HEI has close cooperation with its partners, who offer internships and hire their graduates. However, for this topranked technical state university, it would be a win-win situation for students and the institution to offer more international labor market information delivered by providers, such as goinglobal. com or passportcareer.com. This is particularly interesting because the statements of the graduates showed that the first initiative taken during the job hunting and internship search was going online and searching for potential employers. This would also be a big gain for German students; for international students, this way would open new perspectives for, and additional chances in, other labor markets. Moreover, it would be a relevant source of information about the German and other foreign labor markets, including visa legislation and application practice. 
Regardless of the latest development of specialized job roles, the British HEI where I conducted interviews with graduates has not changed its strategy. All services, such as workshops or one-to-one sessions, are carried out for all students in the same way and career advisers have also been told to focus equally both on national and international students. Apart from that, certain activities have been organized and carried out recently, such as an international career fair or a career project, including career events and webinars for international students, but have not become institutionalized. There are one or two members of staff who act as representatives for such activities. However, it is a small part of their job role. Consequently, the responses of such interviewees regarding international students' needs and services were less sophisticated and focused than those from career specialists. The latter staff appeared to be better trained and educated, particularly in the field of cross-cultural studies.

The findings also imply that non-European students require more specialized services focused on their needs, including the chance to address relevant issues, like being confronted with similar obstacles of entering the British labor market, in a more exclusive setting together with well-trained and experienced counselors. Through such kinds of workshops, where students can share their experience on career planning and management issues, they would find it easier to reevaluate their current situation and probably change their strategy sooner, as some of the graduates did in my sample.

The strategy of the career specialist is only a first stage of a specialization process. A more integrated strategy would be to implement at least two or three career consultants with strong cross-cultural backgrounds in career faculty teams of HEIs. An exceptional example from a UK HEI is a Chinese career adviser who can offer services in English and Mandarin to Chinese students. Besides the language issues, career advisers with a Chinese background may find it easier to target this particular student 
community more effectively and establish a trusting relationship because Chinese students typically tend to stay in their own community.

This outstanding example leads to the consideration of relevant international target groups for HEIs and career services. For instance, a Dutch HEI runs a workshop series in German because Germans are the biggest foreign student community on campus and many of them return home after graduation. In accordance with the Dutch example, it would, therefore, make sense for many British HEIs to offer additional services in Mandarin for Chinese returners, who often prioritize this decision, as reported by the career representatives from the UK and German HEIs.

\section{OTHER INSTITUTIONAL IMPLICATIONS}

The cases analyzed in my sample show that career services can have a positive impact on university graduates' transitions. The narrative of the Nepali graduate is representative for his colleagues from the German HEI:

When I first couldn't find an internship, I realized that I could have reached out to the faculty and to the career center sooner than I did. They are exactly for this purpose to help you and all you have to do is just get in touch with them.

However, these cases also illustrate the fact that some other factors are often much more important for a successful transition and frequently out of the individual's control, creating either chances or obstacles. Such factors depend on the country's policy-makers and its institutions. For instance, the study time in the UK and Germany, visa legislation, certain course designs and the welcoming culture of a society and its economy play important roles. 
As mentioned in Section 3, the internships that graduates carried out in my sample were relevant factors for entering the host labor markets. Only one out of four British interviewees who tried to enter the British labor market finally found a job through a mandatory internship. She was able to convince the management board and received the support needed, including the change in her visa status. If I examine the needs that could be identified among interviewees from the British HEI, then the one-year course design for a full-time master's degree appears to be a very short period of time, especially when internships are included. For a more effective transition, it would be advantageous if the programs could be extended for another term to offer the students and HEIs more flexibility regarding the design, organization and implementation of practical experience. This is a crucial issue for the development of technical skills and professional transition.

The current initiative of the UK's government to allow nonEuropean full-time master's graduates of some HEIs to stay for six months after graduation is certainly well-intended. However, if the findings of the studies are taken into account, then it can be doubted whether this initiative is a successful model for the majority of students with an intention to stay. The British cases indicate that - and this is also illustrated by the German sample and by non-European graduates residing in Germany in general graduates often struggle with finding a job, particularly after graduation. This often results in precarious employment or unemployment (Hanganu, 2015). An Indian graduate exemplifies this:

I applied at many places. I was looking for jobs and I had many interviews, but it was really a very tough time. I was living in (city), but because I didn't have a job, I was staying with my friend in a student hostel. I was staying unofficially with him because I didn't have much money with me. One year was already 
over. So, in the last six months, if I didn't get a job, I had to go back. Luckily, I found a job.

Such situations also arise from a lack of institutional support from HEIs and state institutions after graduation. Consequently, for the UK, it would be more effective to have a mix of longer and more practice-oriented studies plus an extended period of stay. This could enhance the chances of non-European graduates in the UK or international labor markets.

For German HEIs, initiatives for a better cultural preparedness before students begin their courses could probably be more effective. This should include long-term pre-sessional courses in German for developing solid language skills and becoming familiar with the German culture. For Germany, it would be worthwhile to consider such investments, especially for highpotential subjects given the skills shortage in the German labor market. This would be compatible with the welcoming visa legislation and could go hand in hand with a stricter proof of language proficiency prior to studies. It can be assumed that a combination of such initiatives could reduce duration of study and the high dropout rate of 28 percent of international master's students (Heublein et al., 2017). Finally, this could also make the transition into the host labor market easier.

\section{CONCLUSIONS}

The cases of non-European graduates reveal the complex processes of transition, challenging career planning and management of a broad range of non-European graduates who come from various continents and countries. Our study can be seen as a tentative attempt at exploring issues of career development and cross-cultural transition from study to work. Further research could focus on specific target groups of graduates that are relevant for host coun- 
tries or HEIs regarding different home countries, cultural areas or developing nations with the aim to gain more information about developing more target-oriented career services and improving graduates' career development.

Even though the results of our research are not fully representative, new strategies and trends could be identified, such as the role of career specialists for international students or workshops tailored to the needs of strategically relevant foreign student groups, offered in their native languages. Nevertheless, there are still areas that need to be developed, such as recruiting staff with stronger international backgrounds and HR development, including cross-cultural training or career counseling skills in English for non-native speakers, and a closer cooperation with faculties, comprising more curricular career-related and crosscultural learning. The latter point can also provide an opportunity for smaller career centers because, as my cases show, it is not so much the career center seen as an institution as the HEI as such and the quality of its course programs that helps international students to manage their transition from study to work effectively, by including customized internships and employing a more holistic approach to counseling and expert knowledge.

\section{REFERENCES}

Brandl, K. (2015). Ausgangslage der Career Services an deutschen Hochschulen: Bericht zur Umfrage des CSND. Berlin, Germany: CSND.

Coombes, R. (2014). Supporting international students with careers provision: A review of UK higher education careers service provision and a case study based on the University of Exeter. Journal of the National Institute for Career Education and Counselling, 32 (1): 43-48.

Equality Challenge Unit. (2012). Attracting international students: Equitable services and support, campus cohesion and community engagement. London, England: Author. 
Hanganu, E., \& Heß, B. (2014). Beschäftigung ausländischer Absolventen deutscher Hochschulen: Ergebnisse der BAMF-Absolventenstudie 2013. Nuremberg, Germany: BAMF.

Hanganu, E. (2015). Bleibequoten von internationalen Studierenden im Zielstaaten Vergleich. Nuremberg, Germany: BAMF.

Higher Education Statistics Agency. (2016). Employment activity and most important activity by level of qualification obtained and mode of study 2014/15. Retrieved March 28, 2018, from https://www.hesa.ac.uk/files/ dlhe_1415_table_B.xlsx

Heublein, U., Ebert, J., Hutzsch, C., Isleib, S., König, R., Richter, J., \& Woisch, A. (2017). Zwischen Studienerwartungen und Studienwirklichkeit: Ursachen des Studienabbruchs, beruflicher Verbleib der Studienabbrecherinnen und Studienabbrecher und Entwicklung der Studienabbruchquote an deutschen Hochschulen. Hannover, Germany: DZHW.

Home Office. (2018). Statistics on changes in migrants' visa and leave status: 2016. London, England: Home Office.

Leppanen, J., Saarinen, M., Nupponen, M., \& Airas, M. (2014). Hidden competences: Facts and figures. Helsinki, Finland: CIMO.

Mitchell, L.K., \& Krumboltz, J.D. (1996). Krumboltz's learning theory of career choice and counseling. In D. Brown, L. Brooks, \& Associates (Eds.), Career choice and development. San Francisco, CA: Jossey-Bass.

Mühleck, K. (Ed.). (2015). Eurograduate Consortium. Testing the feasibility of European graduate study. Final report of the Eurograduate feasibility study. Hannover, Germany: DZHW.

Network for Innovation in Career Guidance and Counselling in Europe. (2016). European competence standards for the academic training of career practitioners: NICE handbook volume II (edited by C. Schiersmann, S. Einarsdóttir, J. Katsarov, J. Lerkkanen, J. Pouyaud, K. Pukelis, R. Mulvey, \& P. Weber). Opladen: Barbara Budrich.

Prochaska, J.O., DiClemente, C.C., \& Norcross, J.C. (1992). In search of how people change: Applications to addictive behaviors. American Psychologist, 47(9): 1102-1114.

Ripmeester, N., \& Pollock, A. (2013). Willkommen in Deutschland: Wie internationale Studierende den Hochschulstandort Deutschland wahrnehmen. Schriftenreihe Hochschulmarketing 8. Bielefeld, Germany: Bertelmann.

Sykes, B., \& Chaoimh, E.N. (2012). Mobile talent? The staying intentions of international students in five EU countries. SVR's Research Unit, Berlin, Germany: SVR GmbH. 
Tzanakou, C., \& Behle, H. (2017). The intra-European transferability of graduates' skills gained in the UK. Journal of ethnic and migration studies, 43(8), 1379-1397.

Van Mol, C. (2017). Do employers value international study and internships? A comparative study of 31 countries. Geoforum, 78(1): 52-60.

Wiers-Jenssen, J. (2011). Background and employability of mobile vs. non-mobile students. Tertiary Education and Management, 17(2): 79-100.

Yin, R.K. (2009). Case study research: Design and methods. Thousand Oaks, CA: Sage.

Zeltner, E. (2018a). Career services of international students: Comparison of case studies of higher education institutions in Europe. Journal of the National Institute for Career Education and Counselling, 40(1): 33-39.

Zeltner, E. (2018b). Non-European master's graduates in the UK and Germany and their transition from study to work (Unpublished master's dissertation). University of Warwick, Coventry, England.

Zhou, Y., Jindal-Snape, D., Topping, K., \& Todman, J. (2008). Theoretical models of culture shock and adaptation in international students in higher education. Studies in Higher Education, 33, 63-75. 